\title{
Study of prescription pattern of antiglaucoma drugs used in treatment of primary open angle glaucoma in ophthalmology outpatient department of a tertiary care hospital
}

\author{
Manjari Advani, Trupti Jadhao*
}

Department of Pharmacology, LTMMC and GH, Sion, Mumbai, Maharashtra, India

Received: 11 September 2018 Accepted: 05 October 2018

\section{*Correspondence to: \\ Dr. Trupti Jadhao, \\ Email: truptijadhao90@ gmail.com}

Copyright: (C) the author(s), publisher and licensee Medip Academy. This is an openaccess article distributed under the terms of the Creative Commons Attribution NonCommercial License, which permits unrestricted noncommercial use, distribution, and reproduction in any medium, provided the original work is properly cited.

\begin{abstract}
Background: In view of the high prevalence rates and the fact that medication is the primary line of treatment in POAG, an understanding of prescribing patterns can provide an insight into rational use of antiglaucoma drugs.

Methods: This prospective, cross-sectional study was conducted in the glaucoma clinic of a tertiary care teaching hospital over a period of 12 months. Data from prescriptions of patients with POAG was recorded to study the prescribing pattern of antiglaucoma medications, completeness of the prescription and analysis of the prescriber's influence.

Results: Total of 103 prescriptions were included in which all the 141 antiglaucoma drugs were prescribed as eye drops. Average number of drugs prescribed in present study was 1.36. $\beta$ blockers, particularly Timolol (58\%) was the most frequently prescribed drug. Timolol with dorzolamide $(15 \%)$ was the only prescribed fixed dose combination. Prostaglandin analogues $(5 \%)$ were least commonly prescribed. 53\% drugs were prescribed by generic names and $43 \%$ were prescribed from hospital formulary. Instructions regarding the route and frequency of drug administration with duration of treatment were present in all prescriptions; however, instructions regarding method of instillation of eye drops were missing. Authors observed prescriber's influence in present study.

Conclusions: Overall prescribing pattern in our set up is satisfactory. There is a need to sensitize the prescribers regarding the importance of writing method of instillation in prescription as this could improve efficacy reduce side effects, prevent drug wastage and reduce cost. To encourage the physicians for rational prescribing such type of studies should be done more often for periodic auditing of prescriptions.
\end{abstract}

Keywords: Drug utilization study, Dorzolamide, Glaucoma, Timolol, Prescription

\section{INTRODUCTION}

Glaucoma is a leading cause of irreversible blindness throughout the world. ${ }^{1}$ India accounts for $12.9 \%$ primary open angle glaucoma (POAG) blindness and $12.7 \%$ of primary angle closure glaucoma (PACG) blindness in the world..$^{2}$ In view of the high prevalence rates and the fact that medication is the primary line of treatment in POAG, an understanding of prescribing patterns can provide an insight into rational use of antiglaucoma drugs.
Drug utilization research has been defined by WHO as the marketing distribution, prescription and use of drugs in a society with special emphasis on the resulting medical, social and economic consequences. These are powerful exploratory tools to ascertain the role of drugs and their assessment is important for clinical educational and economic purposes. History has taught us that successful research in drug utilization requires multidisciplinary collaboration between clinicians, clinical pharmacologists, 
pharmacists and epidemiologists. Tertiary care hospital provides an ideal setting for this kind of research.

The study of prescribing pattern is a component of medical audit which seeks monitoring, evaluation and necessary modifications in the prescribing practices of the prescribers to achieve rational and cost-effective medical care. Thus, the monitoring of prescription and drug utilizations studies can identify the problem and provide feedback to prescribers so as to create an awareness about irrational use of drugs. Several anti-glaucoma drugs are available in the Indian market for clinicians to choose from and as newer drugs continue to enter, it is not just desirable but imperative to make the efforts to create standards for their rational use.

Patient education regarding proper method of instillation of eye-drops is a very crucial step in pharmacotherapy of glaucoma. This would result, not only, in prevention of infection but also avoid wastage of the drug. As a result, the financial burden to the patient as well as the hospital (where drugs are dispensed free or at subsidized cost to the patients) would be substantially reduced. Such reports from India are few and hence this study was undertaken to create an awareness about rational use of antiglaucoma drugs.

\section{METHODS}

It was a cross-sectional observational study undertaken from February 2016- January 2017 in a tertiary care teaching institute in Maharashtra, India. The study protocol was approved by the Institutional Ethics Committee prior to the commencement of the study. In this study, prescriptions of patients diagnosed as primary open angle glaucoma (POAG) of either sex aged 18 - 65 years were included from the ophthalmology outpatient department of study centre.

After obtaining informed consent from the patients, the following information was captured on a structured case record form: demographic profile, diagnosis, drugs prescribed along with their dose and frequency, written instructions regarding precaution to be taken and method of drug instillation. The designation of the prescribing doctor was also recorded. The following core parameters 3 were then calculated using Microsoft excel:

- Average number of anti-glaucoma drugs prescribed per encounter.

- Percentage of anti-glaucoma drugs prescribed: a) by generic name b) as fixed dose combination (FDC) c) from hospital drug formulary d) having written instruction for precaution and method of drug administration

- Prescriber's influence was analyzed by classifying the prescriptions into those written by ophthalmology faculty (post graduates in ophthalmology and employed as medical teachers) and those by resident doctors (M.B.B.S., pursuing post graduate degree in ophthalmology) and then evaluated according to above parameters.

\section{Statistical analysis}

Statistical analysis was done by using the Microsoft excel.

\section{RESULTS}

A total of 103 prescriptions were analysed in this study. Mean age of patients was 50.58 and $66 \%$ were males. It was observed that beta blocker was prescribed in $58 \%$ prescriptions, making it the most commonly prescribed class of anti-glaucoma drug followed by carbonic anhydrase inhibitor (23\%) and alpha agonist (14\%). Least commonly prescribed were the prostaglandin analogues $(5 \%)$ as shown in Figure 1 and the only FDC prescribed was timolol + dorzolamide $(15 \%)$ as shown in Table 1 .

Table 1: Distribution of total drugs prescribed $(n=141)$.

\begin{tabular}{|ll|}
\hline Drugs prescribed & Number \\
\hline Single drug therapy & \\
\hline Timolol & 55 \\
\hline Brimonidine & 3 \\
\hline Bimatoprost & 2 \\
\hline Latanoprost & 2 \\
\hline Travoprost & 3 \\
\hline FDC & \\
\hline Timolol + Dorzolamide & 21 \\
\hline Dual therapy & \\
\hline Dorzolamide, Brimoidine & $11+11$ \\
\hline Timolol, Brimonidine & $6+6$ \\
\hline Total & 141 \\
\hline
\end{tabular}

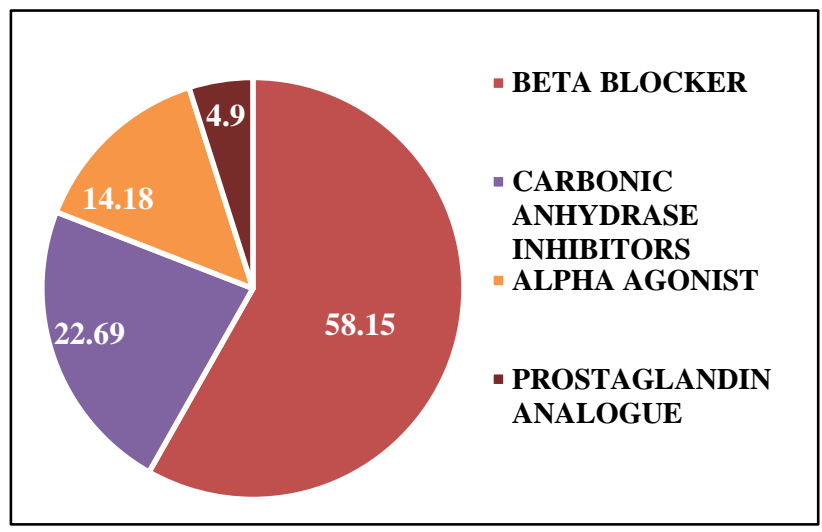

Figure 1: Class wise distribution of anti-glaucoma drugs $(n=141)$.

The prescriptions were divided into three categories on the basis of duration since which patients were on antiglaucoma therapy. The duration of therapy varied from 2 months to 4 years. The total number of patients who were 
on anti-glaucoma therapy for less than 1 year, for $1-2$ years and for more than two years were 44, 44 and 15 respectively as shown in Table 2 .

Table 2: Variation in prescribing pattern of antiglaucoma drug depending on duration of therapy.

\begin{tabular}{|c|c|c|c|}
\hline \multirow[t]{2}{*}{$\begin{array}{l}\text { Drugs } \\
\text { prescribed }\end{array}$} & \multicolumn{3}{|c|}{$\begin{array}{l}\text { Duration of anti-glaucoma } \\
\text { therapy }\end{array}$} \\
\hline & $\begin{array}{l}\text { >1 year } \\
(n=44)\end{array}$ & $\begin{array}{l}1-2 \text { years } \\
(n=44)\end{array}$ & $\begin{array}{l}<2 \text { years } \\
(n=15)\end{array}$ \\
\hline \multicolumn{4}{|c|}{ Single drug therapy } \\
\hline Timolol & 34 & 14 & 7 \\
\hline Brimonidine & 3 & 0 & 0 \\
\hline Bimatoprost & 2 & 0 & 0 \\
\hline Latanoprost & 2 & 0 & 0 \\
\hline Travoprost & 3 & 0 & 0 \\
\hline \multicolumn{4}{|l|}{ FDC } \\
\hline $\begin{array}{l}\text { Timolol }+ \\
\text { Dorzolamide }\end{array}$ & 0 & 17 & 4 \\
\hline \multicolumn{4}{|c|}{ Two drug therapy } \\
\hline $\begin{array}{l}\text { Brimonidine, } \\
\text { Dorzolamide }\end{array}$ & 0 & 9 & 2 \\
\hline $\begin{array}{l}\text { Timolol, } \\
\text { Brimonidine }\end{array}$ & 0 & 4 & 2 \\
\hline
\end{tabular}

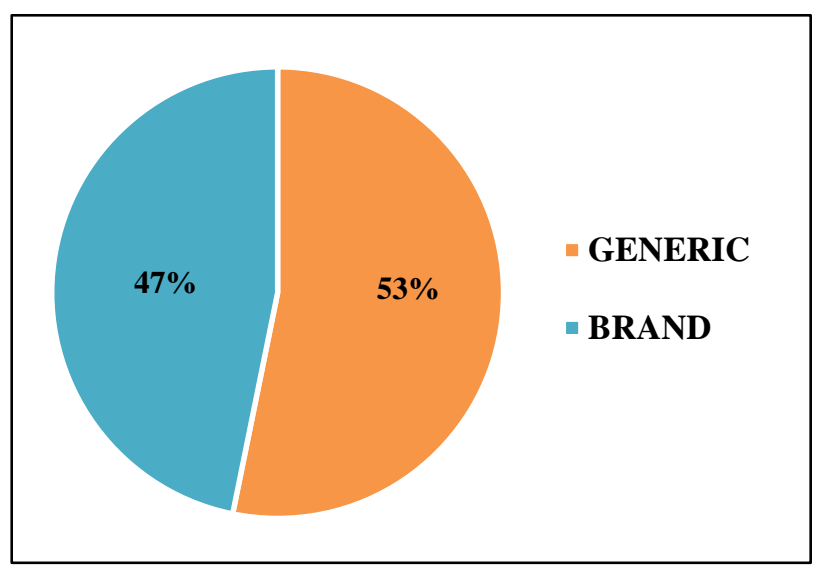

Figure 2: Percentage of anti-glaucoma drugs prescribed by generic and brand name $(n=141)$.

Out of the 141 anti-glaucoma drugs prescribed; $53 \%$ were prescribed by generic name as shown in Figure 2. The only drug prescribed from hospital formulary was Timolol $(43 \%)$ as shown in Figure 3. 61 patients were prescribed timolol either as monotherapy (55) or with brimonidine (6). The FDC of Timolol and dorzolamide, as well as the other drugs were not present in the hospital formulary.

Regarding the prescribers' influence, it was observed that $77 \%$ patients received prescription from faculty and $23 \%$ by resident doctors. Out of 141 drugs prescribed, 111 drugs were prescribed by faculty and 30 by resident doctors as shown in Table 3.
Table 3: Analysis of prescribers' influence on prescriptions.

\begin{tabular}{|lll|}
\hline Parameters & Faculty & Resident \\
\hline $\begin{array}{l}\text { Total number of } \\
\text { prescriptions }\end{array}$ & $79(77 \%)$ & $24(23 \%)$ \\
\hline $\begin{array}{l}\text { Total number of drugs } \\
\text { prescribed }\end{array}$ & 111 & 30 \\
\hline Class of drugs prescribed & $59(53 \%)$ & $23(77 \%)$ \\
\hline Beta blocker & $27(24 \%)$ & $5(16 \%)$ \\
\hline $\begin{array}{l}\text { Carbonic anhydrase } \\
\text { inhibitor }\end{array}$ & $18(16 \%)$ & $2(6 \%)$ \\
\hline Alpha agonists & $7(6 \%)$ & $0(0 \%)$ \\
\hline Prostaglandin analogue & $60(54 \%)$ & $15(50 \%)$ \\
\hline $\begin{array}{l}\text { Drugs prescribed by Generic } \\
\text { name }\end{array}$ & $51(46 \%)$ & $15(50 \%)$ \\
\hline $\begin{array}{l}\text { Drugs prescribed by brand } \\
\text { name }\end{array}$ & $16(14 \%)$ & $5(16 \%)$ \\
\hline Drugs prescribed as FDC & & \\
\hline
\end{tabular}

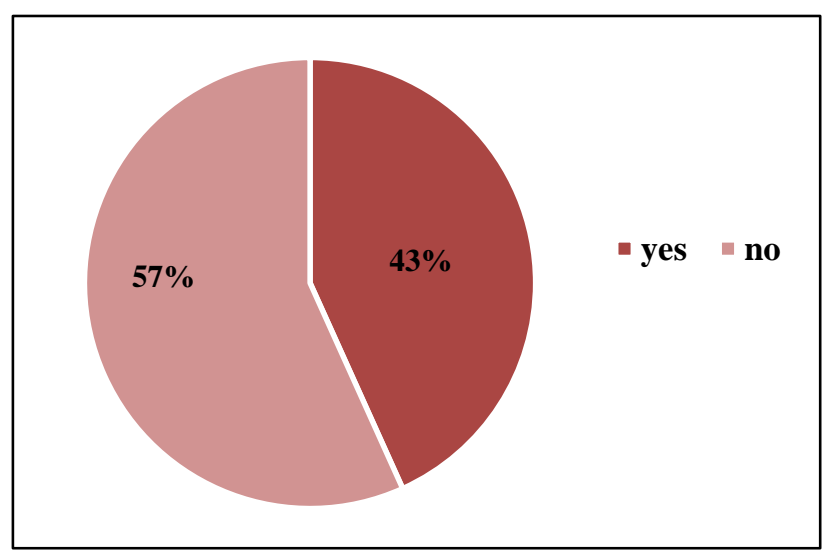

Figure 3: Percentage of drugs prescribed from hospital formulary $(n=141)$.

\section{DISCUSSION}

Glaucoma is the leading cause of blindness in India. ${ }^{1}$ The mainstay of glaucoma therapy is to reduce intraocular pressure by use of medications. Drugs used for treatment of glaucoma either decrease the aqueous humor secretion or increase the reabsorption by enhancement of aqueous outflow. Five general groups of drugs, Parasympathomimetics, carbonic anhydrase inhibitors (CAI's), $\alpha$-agonists, $\beta$ - blockers and prostaglandin analogs are useful in the reduction of intraocular pressure. ${ }^{4,5}$ POAG is a chronic optic neuropathy often requiring lifelong treatment.

Patient compliance, adherence and persistence with therapy play a vital role in improved outcomes by reducing morbidity and the economic consequences that are associated with disease progression. ${ }^{6}$ Hence it is important to periodically evaluate the prescribing patterns and drug utilization of antiglaucoma drugs. 
Average number of drugs prescribed in our study was 1.36 which is in unison with other such studies conducted in India which reported it as 1.23 and $1.8 .^{7,8}$ It has been endorsed that average number of drugs per prescription should be $\leq 2 .{ }^{9}$ It is advisable to keep the number of drug prescriptions as low as possible since higher figures lead to an increased risk of drug interactions and an increase in hospital cost due to errors of prescribing. ${ }^{10}$

Timolol, the most widely prescribed anti-glaucoma drug and it was most commonly prescribed (58\%) in present study as well. ${ }^{7,11}$ Authors observed that timolol was the preferred drug in initiating the therapy of glaucoma and was effective in controlling intra-ocular pressure during the first year of treatment in most cases (34 out of 44). 14 (out of 44) and 7 (out of 15) patients were well controlled on single drug timolol during the second year and third year of treatment. Dorzolamide, a topical carbonic anhydrase inhibitor was the second most common drug prescribed in present study $(23 \%)$ of which $15 \%$ was with timolol as FDC and the remaining $(8 \%)$ in combination with brimonidine. In our set up, the prescribing of dorzolamide was found to be higher as compared to other study where it was reported to be $11.38 \% .^{7}$

In this study prostaglandin analogues were prescribed in $4.9 \%$ of the prescriptions. This usage is very low as compared to other Indian studies in which it was $17.88 \%$ and $8.88 \% .^{7,12}$ Prostaglandin analogues have been found to be superior in efficacy to all other topical classes of glaucoma medications. ${ }^{4}$ However, a study reporting trends in Australia and New Zealand in 2006 has shown that although prostaglandin analogues were the first choice drugs, ophthalmologists favored $\beta$ blockers because of cost, government restrictions and familiarity. ${ }^{13}$ Similarly, higher cost and non-inclusion in hospital formulary may be the reason for lower usage of prostaglandin analogues in a public hospital like ours.

It was observed that at the start of therapy, patients were on monotherapy which is eventually changed to two drug therapy or FDC over a period of 1 year. Initially monotherapy was adequate but as it is a progressive condition two or more anti-glaucoma drugs are required eventually to control IOP and disease progression. This trend is in accordance with the international council of ophthalmology (ICO) guidelines for glaucoma 2015. ${ }^{14}$ Larger studies with intention to know relation between duration of treatment and change of drug therapy can be done in near future for more conclusive results.

Timolol + dorzolamide was the only FDC prescribed in present study. Similar finding was observed in another Indian study which found that $26.66 \%$ of total prescriptions were FDCs and timolol + dorzolamide was the most commonly prescribed amongst them. ${ }^{12}$ It is more convenient (both easier and faster) to in still 1 drop of a fixed combination than 2 drops from separate bottles of the component medications. Use of FDCs thus improve compliance by reducing the number of instillations per day. ${ }^{11}$ So, FDCs if rational, offer benefits of convenience, cost and safety.

In the present study $53 \%$ of the drugs were prescribed by generic name which is higher than $0-10 \%$ as reported by other Indian studies. ${ }^{12,15}$ There is evidence to suggest that generic medicines are as good as branded medicines with regard to bioequivalence and therapeutic equivalence. ${ }^{16,17}$ Medical council of India had called upon doctors practicing medicine to prescribe drugs with generic names, as far as possible. ${ }^{16}$ Although the number of generic prescription in present study is higher than others there is still need for more encouragement.

In the present study $43 \%$ of the drugs were prescribed from the hospital formulary. Timolol and pilocarpine were the anti-glaucoma drugs from the NLEM which were available in our hospital formulary list and this needs to be revised as per current prescribing pattern. ${ }^{18}$

The written instructions regarding dose, dosing interval and duration of therapy were mentioned in all the prescriptions. One Indian study has reported similar result as our whereas in another study instructions were missing in $22.1 \%$ of the total number of drugs prescribed. ${ }^{12,19}$ However, proper instructions for drug instillation were not written in any of the prescriptions. Similar observations were also made in other studies. ${ }^{12,20}$

The instructions regarding drug instillation is important aspect of ocular therapy. Simple procedures like closure of nasolacrimal duct for minutes reduces the incidence of occurrence of systemic toxicity due to decrease in systemic absorption of drug from vascular nasal mucosa. Eyelid closure for 5 minutes after instillation of anti-glaucoma drugs can enhance the efficacy of the treatment by maximizing ocular contact time of the drug.

Frequent blinking following eye drop instillation increases the systemic absorption of a drug as it is pumped into the nasolacrimal system and ultimately exposed to the vascular nasal mucosa. The consistent inclusion of these techniques combined with patient education and written instructions should enhance compliance with appropriate therapy in all patients. ${ }^{21}$ Hence sensitization of the prescribers regarding the importance of written instillation instructions should be promoted.

To improve prescription quality and rationality of drug use, we need to investigate the subjective and objective factors that affect doctors' prescription patterns. The prescriber plays a critical role in determining drug use. ${ }^{3}$ Authors evaluated the influence of prescribers' educational status and work experience on the drug prescribing pattern. $77 \%$ of the prescriptions were written by faculty indicating that patients of glaucoma were seen by senior doctors more often. Both faculty (53\%) and resident doctors (77\%) prescribed beta blockers most frequently. Authors 
observed that other class of drugs like carbonic anhydrase inhibitors, alpha agonist and prostaglandin analogues were prescribed more by the faculty. But this finding cannot be generalized because of the smaller sample size of the present study.

On the basis of observations mentioned authors can conclude that the overall prescribing pattern in authors' set up is satisfactory.

Recent International and National prescribing trends show prostaglandins as first choice of prescriber. However due to higher cost and non-availability in hospital pharmacy, its use has been limited in present study.

Timolol + dorzolamide can be included in hospital formulary as it is the most commonly prescribed effective FDC in present study. This will help in increasing adherence and compliance of patients in glaucoma therapy.

There is a need to sensitize the prescribers regarding the importance of writing method of instillation in prescription as this could improve efficacy reduce side effects, prevent drug wastage and reduce cost.

To encourage the physicians for rational prescribing such type of studies should be done more often for periodic auditing of prescriptions.

\section{ACKNOWLEDGEMENTS}

Authors would like to thank all the staff of Department of Ophthalmology, Sion Hospital, Mumbai, Maharashtra, India for their support and encouragement.

Funding: No funding sources

Conflict of interest: None declared

Ethical approval: The study was approved by the Institutional Ethics Committee

\section{REFERENCES}

1. Tanuj D, Ichhpujani PSR. Glaucoma - leading cause of Blindness. Natl Program Control Blind India Newsl. 2013;Jan-Mar(March):1-8.

2. Klein BE, Klein R, Sponsel WE, Franke T, Cantor LB, Martone J, et al. Prevalence of glaucoma: the Beaver Dam eye study. Ophthalmol. 1992 Oct 1;99(10):1499504.

3. WHO. International WG for drug statistics methodology. Introduction to drug utilization research. Solutions. 2003:1-48.

4. Singh K, Shrivastava A. Medical management of glaucoma: principles and practice. Indian $\mathbf{J}$ Ophthalmol. 2011 Jan;59(Suppl1):S88

5. Parikh RS, Parikh SR, Navin S, Arun E, Thomas R. Practical approach to medical management of glaucoma. Indian J Ophthalmol. 2008 May;56(3):223.
6. Kulkarni SV, Damji KF, Buys YM. Medical management of primary open-angle glaucoma: Best practices associated with enhanced patient compliance and persistency. Patient Preference Adherence. 2008;2:303.

7. Kumar R, Suman P, Ray Mohanty, Deshmukh YA. Drug Utilization studies in Glaucoma patients at MGM medical College and Hospital. Int J sci Res. 2013;433(7):433-5.

8. Mahajan A, Gupta AK, Singh G. A study of prescribing pattern of medical therapy in glaucoma patients. World J Pharm Res. 2016;5(6):1030-43.

9. Mahajan HM, Honrao R, Borkar AS, Badwaik RT, Chopade SS, Surwase P. A drug utilization study in glaucoma patients in a tertiary care hospital of central India. J Cont Med A Dent. 2015;3(2):44-7.

10. Deepalatha C, Pratyusha L. To study the drug use pattern in primary open-angle glaucoma in a tertiary care teaching hospital. Asian J Pharm Clin Res. 2017;10(2):198-200.

11. Sharma R, Khajuria R, Sharma P, Sadhotra P, Kapoor B, Kohli K, et al. Glaucoma therapy: prescribing pattern and cost analysis. JK Sci. 2004;6(2):88-92.

12. Yadav AK, Patel V. Drug use in primary open angle glaucoma: a prospective study at a tertiary care teaching hospital. Indian J Pharmacol. 2013 Mar;45(2):117.

13. Carroll SC, Gaskin BJ, Goldberg I, Danesh-Meyer HV. Glaucoma prescribing trends in Australia and New Zealand. Clin Exp Ophthalmol. 2006 Apr;34(3):213-8.

14. Gupta N, Tin A, Congdon NG, Dada T, Lerner F, Olawoye S, et al. ICO Guidelines for Glaucoma Eye Care. Int Counc Ophthalmol. 2015. Available at: http://www.icoph.org/downloads/ICOGlaucomaGuid elines.pdf.

15. Ahmed QS, Sayedda K, Agarwal A, Ansari NA. Drug utilization study of antiglaucoma drugs in a tertiary care teaching hospital, Bareilly. World J Pharmaceut Res. 2013;3(2):2420-8.

16. Andrade C, Rao TS. Prescription writing: generic or brand?. Indian J Psychiatry. 2017 Apr;59(2):133.

17. Gagne JJ, Polinski JM, Jiang W, Dutcher SK, Xie J, Lii J, et al. Outcomes associated with generic drugs approved using product-specific determinations of therapeutic equivalence. Drugs. 2017 Mar 1;77(4):427-33.

18. Ministry of health and family welfare. Nlem India $2015 . \quad$ Available at: http://cdsco.nic.in/WriteReadData/NLEM2015/NLEM, 2015.pdf.

19. Biswas NR, Jindal S, Siddiquei MM, Maini R. Patterns of prescription and drug use in ophthalmology in a tertiary hospital in Delhi. Br J Clin Pharmacol. 2001 Mar;51(3):267-9.

20. Flach AJ. The importance of eyelid closure and nasolacrimal occlusion following the ocular instillation of topical glaucoma medications, and the need for the universal inclusion of one of these 
techniques in all patient treatments and clinical studies. Transactions Am Ophthalmol Soc. 2008 Dec;106:138.
Cite this article as: Advani M, Jadhao T. Study of prescription pattern of antiglaucoma drugs used in treatment of primary open angle glaucoma in ophthalmology outpatient department of a tertiary care hospital. Int J Basic Clin Pharmacol 2018;7:2228-33. 